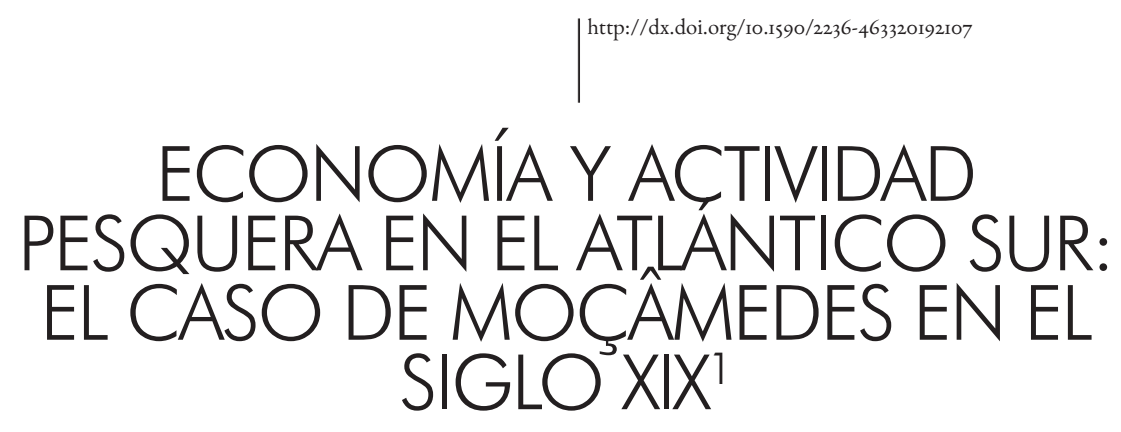

(1D) Laila Brichta ${ }^{2 ; 3}$

\title{
RESUMEN
}

Este trabajo tiene por objetivos analizar Moçâmedes durante el siglo XIX y su importancia para el desarrollo del sur de Angola y para el comercio con otros puertos en África y con Portugal. Se observa que las principales mercancías de exportación fueron aquellas derivadas de la pesca en las aguas frías de su litoral y no las derivadas de la agricultura, como parecía ser la intención primera de los colonos que allí llegaron y del estado portugués, que promovió la colonización. El comercio de alimentos, que incluyen el pescado, el ganado y diversos géneros de huerta, fue fundamental para el desarrollo de Moçâmedes, para los cambios económicos con distintos sitios y pueblos, tanto africanos como extranjeros, y para el proceso de ocupación que Portugal implementó en Angola.

\section{PALAVRAS CLAVE}

$$
\text { Angola-colonización - industria pesquera - comercio. }
$$

I Este artículo es uno de los resultados del posdoctorado desarrollado en La Universidad de Las Palmas de Gran Canaria entre 2017 y 2018 , actividad posible por el alejamiento de las actividades académicas con la financiación y la autorización de la Universidad Estadual de Santa Cruz (Uesc, Ilhéus, en Bahía, Brasil); contó con ayuda del proyecto de investigaciones Moçâmedes: relações entre Angola, Brasile Portugal no século XIX financiado por la agencia CNPq por la chamada MCTI/ CNPA/MEC/CAPES n ${ }^{\circ}$. 22/2014.

2 Universidade Estadual de Santa Cruz. Ilhéus - Bahia - Brasil.

3 Profesora de Historia de la Universidad Estadual de Santa Cruz (UESC) en Brasil; vice-coordinadora del curso de Maestría de Historia del Atlántico y de la Diáspora Africana. Imparte clases de Historia de Brasil, Historia de África y Historia de América en especial durante la época contemporánea. Investigadora del Laboratorio Atlantis con el desarrollo de investigaciones sobre la Historia de Angola en siglos XIX y XX. Aborda sobre todo cuestiones de política, cultura y de la formación de las sociedades. Entre 2017 y 2018 ha realizado una estancia de pos-doctorado en la Universidad de Las Palmas de Gran Canaria (ULPGC). 


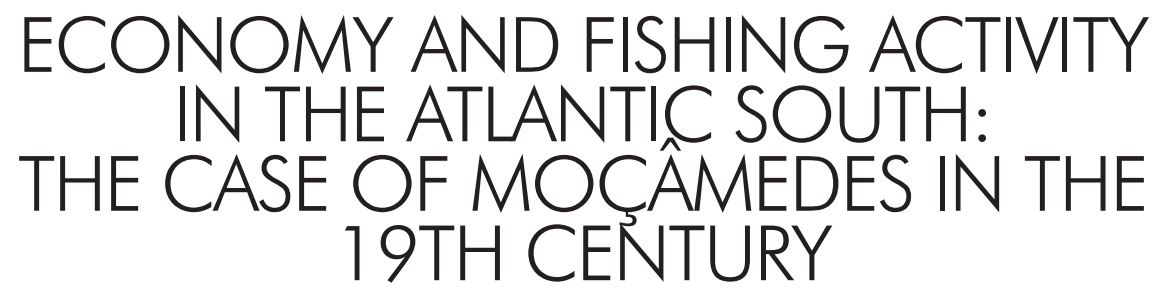

(D) Laila Brichta

\section{ABSTRACT}

This work analyzes Moçâmedes during the 19th century and its importance for the development of southern Angola and for trade with other ports in Africa and Portugal. It is observed that the main export goods were those derived from fishing in the cold waters of its coast and not those derived from agriculture, as it seemed to be the first intention of the settlers who arrived there and of the Portuguese state, which promoted colonization. The food trade, including fish, cattle and various garden species, was essential to the development of Moçâmedes, also to economic changes with different places and peoples, both African and foreign, and to the process of occupation that Portugal implemented in Angola.

\section{KEYWORDS}

Angola - colonization - fishing industry - trade. 


\section{Introducción}

$\mathrm{L}$ a industria pesquera crece en todo el mundo y se vuelve, cada vez más, una alternativa de suministro de proteína de origen animal para una población mundial que aumenta todos los años. Alimentar a esta población de manera sustentable, que no destruya el planeta, es una cuestión adicional y de gran relevancia hoy en día. Una muestra de la importancia del tema es que la Organización de las Naciones Unidas para la Alimentación y Agricultura (FAO) creó una sección para reglamentar y controlar la pesca en todo el globo, una vez que la falta de conciencia de los agentes involucrados en esta actividad y la búsqueda desenfrenada de beneficios ya ha provocado la extinción de algunas especies de animales acuáticos y pone en riesgo tantas otras, lo que puede afectar la alimentación futura de la humanidad ${ }^{4}$.

Algunos países desarrollan la pesca industrial marítima o acuática y en grandes proporciones, como China, Indonesia, EUA y Rusia entre otros, que faenan sobre todo en el Pacífico y en Atlántico Norte. ${ }^{5}$ Sin embargo, aunque la industria pesquera de países como Angola y Namibia no sea tan desarrollada, hay mucho potencial en las aguas que bañan sus litorales, de forma que constituyen una zona importante de la pesca en el Atlántico Sur.

La actividad pesquera en la costa angoleña tiene ya una historia larga y que articula proyectos de colonización de europeos en África con un sistema-mundo capitalista promotor de la interacción de todos los sitios, de modo que cada uno, por menor que sea geográficamente y por menor sea su producción económica, contribuya para el desarrollo del mismo sistema, aunque este no sea justo para todos ${ }^{6}$.

4 ONU. El estado mundial de la pesca y la acuicultura 2016. Contribución a la seguridad alimentaria y la nutrición para todos. Roma: 2016. Disponible en: <http://www.fao.org/publications/sofia/ sofia/es/>. Consultado el 30 enero 2018.

5 Ibidem. p.11

6 WALLERSTEIN, Immanuel .Capitalismo Histórico e Civilização capitalista. Rio de Janeiro: Contraponto, 2001. 
Fue con los portugueses llegados y establecidos en el sur de Angola, en el siglo XIX, que la pesca se convirtió en una actividad comercial en la zona, al tiempo que ayudó a la fijación de un sistema de ocupación de las tierras africanas por los europeos y colaboró para la inserción definitiva de la región en el sistema-mundo capitalista.

Además, la cuestión de cómo alimentar una población en crecimiento fue muy importante también en los siglos pasados y para los pueblos en expansión territorial. Se puede decir que uno de los criterios para la elección de un determinado sitio para vivir en sociedad es precisamente la posibilidad de obtener comida. La proteína animal es un alimento tan importante para algunas culturas que su búsqueda justificó algunos emprendimientos que involucraban grandes riesgos. Esto fue lo que sucedió, por ejemplo, con los españoles en el archipiélago canario y con el desarrollo de la pesca marítima en el banco sahariano en los siglos XVII y XVIII7 . Lo mismo con una naturaleza un poco distinta, pero aún dentro del proceso de la expansión de europeos que se mantuvo durante el siglo XIX, la preocupación con la búsqueda de comida también afectó a los portugueses en el sur de Angola. Aunque no se fomentó una industria pesquera con las mismas dimensiones que la de Canarias, Moçâmedes tuvo un impulso con la actividad pesquera empezada por los colonos portugueses que le permitió ampliar la práctica comercial con diversas poblaciones y naciones.

\section{Lisas, pargos y corvinas}

Por supuesto que antes de la llegada de los portugueses al sur de Angola diversas poblaciones africanas practicaban la pesca, especial-

7 SANTANA Juan Manuel e SANTANA. Germán. La pesca en el banco sahariano, siglos XVII y XVIII. Madrid: Catarata, 2014. 
mente en los ríos y lagos. ${ }^{8}$ Sin embargo, la cultura pesquera no fue una actividad comercial de muchos de ellos. Los nativos de esa zona, a principios del siglo XIX, tanto del grupo herero como los designados en aquel momento de mucubaes y mondombes, desarrollaron mucho más la actividad de creación de ganado para el comercio, al igual que la agricultura para la alimentación, como vemos en este informe del Gobernador de Moçâmedes, Joaquim José da Graça, a finales de la década de 1860:

Os mondombes vivem nos mattos, pastoreando os seus gados e cultivando as terras altas, d'onde colhem os seus mantimentos; os mucuissos não tem pousada certa, vivem nos rochedos, alimentando-se de mariscos e de algum peixe que podem pescar nas praias, mas sem aparelho para a industria da pesca mais que a destreza e algum pedaço de ferro e pau, que o acaso lhe depara; os mucubaes vivem de pilhagem, enquanto os munanos lhe dão tempo para isso, porque estes, muito poderosos em números e em valor, quando saem a campo é somente para se apoderarem dos gados que encontram (... $)^{9}$

En este pequeño relato percibimos, en una visión limitada de un hombre europeo del siglo XIX, la presencia de la actividad pesquera en algunos pueblos africanos, como para los llamados mucuissos. ${ }^{10}$ Cuando comparamos el énfasis dado a la actividad de pesca de estos africanos con el que se dio a la creación del ganado, notamos la importancia de esta segunda actividad, en detrimento de la primera.

8 MEDEIROS, Isabel. Contribuição para o estudo da colonização e pesca no litoral de Angola ao sul de Benguela. In: Col. EstudosEnsaios e Documentos. IICT, Lisboa, n. 140, 1986.

9 GRAÇA, Joaquim José da. Relatórios de seugoverno. apud ARANHA, Brito. Memórias histórico-estatísticas de algunas villas e povoações de Portugal. Lisboa: Livraria de A. M. Pereira, p. 268. El destaque de los nombres está en el documento original. En todo el artículo se optó por mantener las transcripciones en la lengua y la grafía encontrada en las fuentes consultadas.

10 Para empezar una lectura etnográfica, véase ESTERMANN, C. Etnografia do Sudoeste Africano. Lisboa: Junta de Investigação do Ultramar, vol. III, 1961. Este investigador llamó a esta población cuissos y los definió como naturales de altiplanicies, pero que iban al litoral para desarrollar la pesca. 
Los portugueses que residieron en Moçâmedes no depositaron en la actividad pesquera sus primeras inversiones de capital y gente, aunque la enorme cantidad de pescado en el mar que baña la costa sur de Angola había llamado la atención de todos los viajantes europeos, desde Diogo Cão, que pasó por la región en 1486, y Duarte Pacheco Pereira, que empezó a redactar su obra alrededor de $1505{ }^{11}$

A finales del siglo XVIII, con la expedición encargada por el Gobernador General de Angola, el Barón de Mossamedes, al sargento-mor Gregório José Mendes en 1785, también encontramos referencias a la existencia de «excelentes lisas, pargos y corvinas» ${ }^{12}$. Más tarde llegaron los ingleses que llamaron a la bahía de Moçâmedes Little Fish Bay ${ }^{13}$ y los franceses, que a través de la expedición de Jean Baptiste Douville (1827) también relataron la riqueza de las aguas ${ }^{14}$. Pero el decisivo informe fue redactado por los expedicionarios portugueses en 1839, como leemos en el siguiente pasaje escrito por el capitán Pedro Alexandrino da Cunha:

É de notar que os nativos d'esta bahia têm decidido horror ao peixe, quando os do porto Pinda, que d'estes tão proximos estão, o pescam e comem com avidez, estando uns e outros na costa do mar; e por isso o peixe frequenta esta bahia em tão grande quantidade não sendo ali molestado. ${ }^{15}$

La bahía a la que se refería el capitán es la de Moçâmedes, adonde fue enviado a cargo del Gobernador General de Angola con el propó-

11 PACHECO, Duarte.Esmeraldo de Situ Orbis. Lisboa, ImprensaNacional, 1892, pp. 85-86. Disponible en: <http://www2.senado.leg.br/bdsf/handle/id/242845>.Consultado el 12 marzo 2018.

12 ARANHA, Brito. Op. Cit., p.278.

13 VILELA, José (1923) apud MENDES, António. Pesca em Portugal: Ultramar: umapontamento histórico. In: Revista Portuguesa de CiênciasVeterinárias. No 100, 2005. p. 20.

14 AZEVEDO, José Manuel de. Colonização do sudoeste angolano: do deserto no Namibeaoplanalto da Huíla, 1849-1900. Tesis Doctoral. Salamanca: Universidad de Salamanca, 2014. p.46.

15 CUNHA, Pedro Alexandrino. Exploração dos portugueses na costa occidental D’Áfricaem 1839. In: Annaes Marítimos e Coloniais. Lisboa: Imprensa Nacional, $n^{\circ} 12,5^{a}$ série, 1845. p. 482. 
sito de encontrar, entre Benguela y la desembocadura del río Cunene, un buen sitio para la instalación de una fortaleza y para el desarrollo de una colonización, con factorías comerciales. El «Porto do Pinda» se localiza en la ciudad que actualmente se llama Tômbwa, que ya se llamó Porto Alexandre y que se encuentra a alrededor de $90 \mathrm{~km}$ al sur de la ciudad de Moçâmedes. O sea, el militar nos indicó, en su informe, como antes lo hicieron otros, que la pesca podría ser, y de hecho fue, una opción alimentaria de algunos pueblos africanos, aunque no para todos.

Al analizar la documentación disponible, nos damos cuenta de que la pesca no se ha convertido en una actividad comercial para muchos de los pueblos de esta zona hasta, al menos, el siglo XIX, así como ocurrió también con los portugueses que vivían en Angola. Lo mismo ocurre con la presencia en la costa atlántica africana desde el siglo XV, la pesca no fue una actividad comercial de gran relevancia para los portugueses lo que perdura hasta, al menos, mediados del siglo XIX, cuando el sur de este territorio pasó a ser un área de interés estratégico para el Imperio Colonial Ultramarino. Portugal pasó a ocupar toda la costa angoleña, enviando para el sur más recursos militares y, sobre todo, colonos para el propósito de colonizar la zona.

Con el tiempo y la presencia de los portugueses, la población de europeos aumentó en el sur de Angola, especialmente en Moçâmedes, y con ellos, la industria pesquera se ha convertido, durante la segunda mitad del ochocientos, en un producto económico estable y siempre presente en la tabla de exportación de la provincia. Sin embargo, fue una mercancía muchas veces poco valorada y no siempre la más rentable para el Estado colonial, puesto que los portugueses prefirieron insistir en la producción de géneros agrícolas tropicales para exportación y en la extracción vegetal, animal y mineral, desarrolladas con la ocupación colonial. 


\section{La ocupación de Moçâmedes}

La ocupación del territorio al sur de Benguela ya ha sido, de manera que ya se conoce la historia de la llegada de los portugueses desde finales del siglo XVIII, con la expedición encomendada por el Gobernador General de Angola. ${ }^{16}$ Después de esta, otra expedición que tuvo lugar cerca de cincuenta años más tarde, a finales de 1839, promovió la construcción de un fuerte, el Forte de São Fernando, y se definió el establecimiento de las primeras ocho factorías comerciales en la costa de Moçâmedes, lo que ha impulsado, de hecho, una ocupación de la región por los portugueses. Y así, cuando llegó al puerto de Moçâmedes en agosto de 1849 la tercera expedición, en el barco brasileño Tentativa Feliz, con cerca de 140 pasajeros para implementar una colonia agrícola, ya había en el pueblo una muy diminuta población de pescadores entre los cerca de 70 habitantes europeos que vivían allí. $^{17}$

Una persona importante para el proyecto de colonización portugués, y para la expedición que salió de Pernambuco, fue el marqués Sá da Bandeira. Mientras fuera ministro del Ultramar, Sá da Bandeira estimuló intentos para la ocupación de Angola, como la autorización de esa expedición al sur de la provincia, en 1839. En ese mismo año, un equipo que salió de Benguela se dirigió a la región de Moçâmedes con el objetivo de encontrar la mejor ubicación posible un sitio para la construcción de una fortaleza donde se pudiese extender una bandera portuguesa que simbolizase el control de aquellas tierras. ${ }^{18}$

Para tal proyecto, el Gobernador General de Angola en aquel momento, Antonio Manuel de Noronha, nombró y envió al capitán Pedro Alexandrino da Cunha para llevar a cabo el reconocimiento de la zona

16 Ver el detallado trabajo de TORRES, Manuel Júlio. O Distrito de Moçâmedes: nas fases da origem a da primeiraorganização (1485-1859). Lisboa: AgênciaGeral do Ultramar, 1950.

17 ARANHA, Brito. Op. Cit. p. 237.

18 SÁ DA BANDEIRA, Visconde. Instruções de 1838. Citado en TORRES, Júlio. Op. Cit. p. 74. El ministro del Ultramar, en sus instrucciones, se dirigía al gobernador general de Angola ante la inminencia de la segunda expedición. 
y elegir el lugar. El militar viajó por mar con la tarea de encontrar un sitio para la construcción de un fuerte, que recibió el nombre de San Fernando y que fue construido en la bahía llamada Angra del Negro, precisamente en la Punta Negra. En esta expedición iba también un emprendedor particular llamado Antonio Joaquim Guimarães Junior que viajó para fundar la primera factoría comercial, autorizada por el gobierno portugués. ${ }^{19} \mathrm{Al}$ mismo tiempo, salía de Benguela por tierra el teniente João Francisco García con el mismo destino y con la tarea de conocer el interior e intentar establecer relaciones con los sobas locales, lo que logró en Quilengues, Jau, Huíla y Bumbo. ${ }^{20}$

Con esta expedición se fundó, al año siguiente, una fortaleza que también fuera presidio-y la primera factoría en 1840. Y aunque sea un marco en la cronología de la ciudad, dicha factoría no tuvo mucho éxito, debido a problemas con el comerciante Antonio J. Guimarães Junior, que le hicieron abandonar la empresa. ${ }^{21}$ Durante los cinco años siguientes, otros emprendedores particulares también trataron de establecerse en Moçâmedes, mudándose a la región o enviando representaciones para la construcción de factorías comerciales y agrícolas. Según una sugerencia del cronista Luz Soriano, las personas que se dirigían a Moçâmedes fueron, inicialmente, estimuladas por la posibilidad del desarrollo del trato esclavista, que ya sabemos era ilegal en este momento, pero no tuvieron mucho éxito:

19 ARANHA, Brito. Op. Cit.,p. 230.

20 CUNHA, Pedro Alexandrino da. Op. Cit. p. 475-476.

21 GUIMARÃES JUNIOR, Antonio Joaquim. Memorias sobre a exploraçãoaosul da costa de Benguela na África Occidental e fundação do primeiro estabelecimento comercial na Bahia de Mossamedes. Lisboa: Tipografia de F. C. A, 1842. 
(...) as feitorias dos particulares, se não tinham definhado, também não tinham progredido, já porque os hábitos dos moradores de Loanda, e Benguella, opunham rivalidades à prosperidade de Moçâmedes, já porque alguns dos feitores se não tenham esmerado em corresponder à confiança, que neles depositaram os seus commitentes, e já finalmente por não acharem alli o campo, que imaginavam para estabelecer o tráfico da escravatura. ${ }^{22}$

Luz Soriano escribió estas palabras en 1846, cuando las primeras factorías aún estaban en actividad. Pero en poco tiempo se fueron cerrando, o cambiando de sitio o de naturaleza comercial. El comercio de esclavos se había practicado en el pasado de manera más informal en las márgenes de la región y en menor cantidad que en los puertos de Luanda y Benguela; ${ }^{23}$ debió de haber sido mucho más rentable que cualquier otra actividad en aquel momento por lo que habría estimulado a los particulares. También el Visconde de Giraúl, al escribir en 1901 que la antigua Angra del Negro "possuía apenas duas casas que serviam de entreposto no tráfico da escravatura» puso a Moçâmedes en el mapa del comercio de esclavos. ${ }^{24}$

Mientras tanto, este comercio ilegal e infame no fue contemplado por la historiografía oficial — ni por la memoria - como el elemento fundador de la colonización. Pero sí el establecimiento de haciendas agrícolas de azúcar y algodón, y el comercio con los pueblos del interior. O sea, el comercio legal de productos tropicales y de artefactos diversos con los africanos. Sin embargo, aparentemente la actividad

22 LUZ SORIANO, Simão José da. Memória sobre os sertões e a costa sul de Benguella na Província de Angola. En: Annaes Marítimos e Colonias. Lisboa: Imprensa Nacional, $\mathrm{n}^{\circ} 3{ }^{6} 6^{\mathrm{a}}$ série, 1846, p.87.

23 MILLER, Joseph. Way of Death: merchntcapitalim and the Angola slavytrade, 1730-1830. Wisconsin: University of Wisconsin Press, 1988. p. 17.

24VISCONDE DE GIRAÚL. Colonização europeia da província de Angola. Lisboa: Imprensa Nacional, 1901. p.24. 
de pesca no fue considerada por algunos especialistas un hecho importante para la región de Moçâmedes.

Las primeras factorías creadas pertenecieron a las siguientes personas: de Antonio Guimarães Junior en 1840; de Teniente García, solicitada en el año de 1840, pero no concretizada; de Bernardino José Brochado en sociedad con D. Ana Ubertal, creada en el año de 1841; de Clemente Eleutério Freire en sociedad con José Maria de Sousa e Almeida, en 1841; de José Maria Teixeira Caravela, en 1841; de Fernando José Cardoso Guimarães en sociedad con Luiz Batista Fino y Anna Joaquina dos Santos e Silva, de Luanda, en 1843; de Venâncio António da Silva, en 1844; de João António Magalhães en sociedad con Augusto Garrido, en 1845; de João Pinto Gonçalves, en $1843 .{ }^{25}$

De dichas factorías, solo la de Fernando José Cardoso Guimarães logró éxito, aunque por la pesquería que montó y no por la producción agrícola. La industria azucarera parece haber sido la intención primera de Anna Joaquina dos Santos e Silva, socia de esta empresa y notable empresaria angoleña en la primera mitad del siglo XIX, propietaria incluso de cañaverales en la región de Luanda. ${ }^{26}$ Aparentemente también pretendió desarrollar la pesca, puesto que hay registro de que había enviado esclavos y equipamientos para tal práctica, según un informe de Bernardino Freire de Figueiredo algunos años más tarde. ${ }^{27}$

Otro nombre importante de esta época, que contribuyó para el éxito del proceso de colonización de los portugueses en el sur de Angola, fue el de Bernardino Brochado. Este hombre trasladó su huerta al interior del distrito, a la zona llamada Bumbo y empezó a producir géneros para exportaciones y para consumo local, y permaneció

25 AZEVEDO, José Manuel de. Op. Cit. p.67-68.

26 FERREIRA, Roquinaldo. Abolicionismo versus colonialismo: rupturas e continuidades em Angola (século XIX). In: GUEDES, Roberto (org.) África: brasileira e portuguesa - séculos XVI -XIX. Rio de Janeiro: Mauad X. 2013.

27 Bernardino Freire de Figueiredo. "Ofício de 27 de novembro de 1856 ao Vice Presidente da Câmara” apud FELNER, Alfredo. Apontamentos sobre a colonização dos planaltos e litoral do Sul de Angola. Lisboa: AgênciaGeral do Ultramar, 1940. 
en Moçâmedes hasta su muerte como un ilustre colono, en el año de $1868 .^{28} \mathrm{El}$ comercio de géneros alimenticios - realizado tanto con los pueblos y habitantes locales como con otros distritos y con las embarcaciones extranjeras que llegaban al puerto de Moçâmedes - también fue importante para el desarrollo del sur de Angola.

Pero sin duda el mayor impulso para la creación de nuevas casas comerciales, la práctica de la agricultura con vistas a la exportación y el crecimiento regional ocurrió con la llegada de los portugueses provenientes de Pernambuco, en 1849, para el desarrollo de las colonias agrícolas. A partir de estos inmigrantes, y de los que los que vinieron a continuación, la zona pasó a ser más poblada, como se comprueba en una extensa documentación y en la memoria de las personas de Moçâmedes, y además contada por la literatura, como a través de la novela histórica Uma fazenda em África. ${ }^{29}$

\section{Azúcar y Aguardiente, Algodón y Café}

Hasta aquí, estos hechos son conocidos y se registran en diversos escritos. Sin embargo, lo más interesante y poco investigado es que al menos desde la expedición liderada por el capitán Pedro Alexandrino da Cunha, en el año de 1839 - para reconocimiento del sitio donde construir una fortaleza y para desarrollar una nueva colonia al sur de Benguela-la existencia de pescado en las aguas de Moçâmedes fue relatada con entusiasmo. Tal vez porque haya contribuido para la supervivencia de la tropa, como reporta el capitán:

28 TORRES, Manuel Júlio. Op. Cit.

29 MARQUES, João Pedro. UmaFazenda em África. Lisboa: Editora Porto, 2012. 
O peixe abunda na bahia em tão grande quantidade, que em todo o tempo que ali me demorei pescava diariamente em hora e meia até duas horas da manhã dez a quinze arrobas, pela maior parte de muito bom pargo, que de muito me servia para sustento da guarnição, dando-lhe de uma a duas libras de peixe ao almoço, e ceia, pois que a este tempo já os mantimentos do navios estavam exaustos. ${ }^{30}$

Aunque los peces fueran abundantes en las aguas que bañan el sur de Angola, no fue esta la principal razón para el establecimiento de un proyecto de colonización. No se pensaba en la pesca como actividad comercial a partir de la cual se podría emprender un proyecto de asentamiento, solo se empleaba para la alimentación inmediata cuando no había otra fuente de proteína animal. Tampoco se proyectaba su comercialización y la de sus derivados, ni la creación de una industria pesquera, como en poco tiempo se verificó, y que, de hecho, estimuló la fundación de colonias pesqueras de origen lusitano. Probablemente porque aún se creía que la región era propia para la reproducción del modelo de agrocomercio de exportación que caracterizó la economía portuguesa durante tres siglos y que se desarrolló en la colonia de América, cuyo principal producto fue el azúcar. Y ese artículo parecía ser la mercancía más deseada por los colonos que llegaban de Brasil en 1849 y, por supuesto, del gobierno portugués, promotor de la acción colonizadora.

Con la independencia de su colonia americana en 1822, Portugal regresó a África con la intención de reproducir un «nuevo Brasil», como se decía en aquella época. ${ }^{31}$ Buscó desarrollar la agricultura de géneros tropicales o practicar la recolección de caucho, cera, orchilla, goma, marfil y la extracción mineral de cobre y hierro, por ejemplo. Y

30 CUNHA, Pedro Alexandrino da. Op. Cit.

31 ALEXANDRE, Valentin. A desagregação do Império Luso-Brasileiro. In: Nova História da Expansão Portuguesa: o Império Africano, 1825-1890. Lisboa: Editorial Estampa, 1998. 
a pesar de la gran posibilidad de fomentar la pesca y de la llegada de colonos portugueses algarvios, a partir de la década de 1860. Cuando empezaron a irse a Moçâmedes con el propósito de practicar la pes$c a,{ }^{32}$ esta no parecía ser la actividad que Lisboa deseaba desarrollar en sus colonias, aunque fuera la principal economía de Moçâmedes durante mucho tiempo. Los portugueses insistieron en los productos agrícolas tropicales, en especial la caña de azúcar, algodón y café. Estos fueron los productos agrícolas que los portugueses trataron de cultivar en la región, y para eso distribuyeron tierras, herramientas y ofrecieron un sueldo saldo inicial a quienes se aventurasen y llegasen a construir casas para atraer a nuevos colonos, como ocurrió en el altiplano Huila ${ }^{33}$.

Los primeros agricultores europeos en Moçâmedes no tuvieron el éxito esperado, incluso muchos colonos venidos de Brasil prefirieron marcharse a otras localidades, dejando Moçâmedes al principio de la ocupación ${ }^{34}$. Además de la dificultad que tenían para adaptarse al trabajo de la tierra, aquellas personas, que no eran campesinas, sino que trabajaban en la ciudad (en especial los que provenían de Brasil, los lusobrasileños) ${ }^{35}$, muchos colonos tuvieron que pelear con las malas condiciones climáticas de una región casi desértica y con un régimen pluviómetro escaso. Así, además de esa primera dificultad encontrada por los recién llegados portugueses, tampoco fue posible producir un azúcar de buena calidad para la exportación. Así, se deduce incluso de las primeras muestras que obtuvieron los colonos, como se percibe con la carta enviada al ministro del Ultramar, por el Secretario del Gobierno de Moçâmedes, José Herculano da Horta, en 1852:

32 MEDEIROS, Isabel. Op.Cit.

33 AZEVEDO, José Manuel de. Op. Cit. p.165.

34 Ver, por ejemplo, la denuncia de abandono de la colonia hecha por Fernando da Costa Leal, el Gobernador de Mossamedes, en 1855. AHU. Angola, Conselho Ultramarino, cx. 22, lo 2 , nº 117.

35 BRICHTA, Laila. Una travesía hasta Moçâmedes: migraciones atlánticas y la creación de una ciudad en el sur de Angola en el siglo XIX. In: Batey: Revista Cubana de Antropología Sociocultural. Vol. 11, año 2018. 
Este assucar foi obtido por uma experiencia que o governo deste districto quiz fazer com o fim d'animar a colonia agricola, aproveitando para isso d'uma porção de canna que lhe ofereceu o Propietário Fernando José Cardoso Guimarães, pequena porção que apenas produziu 16 arrobas em bruto. Não mandarei a V.Ex ${ }^{a}$ as exagerações dos Colonos que assistirão ao seu fabrico, limitando-me a dizer a opinião dos mais entendidos: $1^{\circ}$ que o assucar he de tão bôa ou melhor qualidade que o do Brazil: $2^{\circ}$ que a cana produz pelo menos mais 25 por cento do que se obtemn'aquelle Paiz. ${ }^{36}$

El propietario Fernando José Cardoso Guimarães es el mismo que ya desarrollaba la pesca y estaba en Moçâmedes desde 1843. El entusiasmo de la gente con estas muestras, que se creían de mejor calidad y más productiva que la caña del Brasil, no duró mucho tiempo. Moçâmedes no se logró convertirse en productora de azúcar, tal vez porque las condiciones de su proceso industrial no produjeran una mercancía de calidad. En un informe de Bernardino Freire de Figueiredo, en el año de 1855, este colono sugiere que el barro de toda la región de Moçâmedes, con el que se hacia el proceso de purga del azúcar, no era apropiado. Sospechaba que el problema se debiera a la sal que contenía el barro y probó otros procesos de limpieza del azúcar, pero, aun así, no logró una producción con la calidad necesaria para la competencia comercial. ${ }^{37}$ Además, a pesar de la intención de Portugal de reproducir en el sur de Angola las circunstancias del nordeste brasileño, uno de los mayores productores de azúcar del mundo, este territorio africano continuó importando azúcar en el siglo XIX, incluso de Brasil.

La caña de azúcar fue sumamente importante para la economía angoleña, pues de ella se hacía también el aguardiente, que fue una de las mercancías más importantes para Angola y, por supuesto, para

36 AHU. Angola. Conselho Ultramarino, 1. 15, $\mathrm{n}^{\circ} 35$.

37 AHU. Pasta Angola. Correspondência com Bernardino Freire de Figueiredo de Abreu e Castro.

Lote $2, \mathrm{n}^{\circ} 285$, doc. de novembro de 1855 . 
Portugal en aquel momento. El aguardiente se producía para el consumo interno de la provincia y para exportación a otras posesiones africanas. Las haciendas azucareras dedicadas a la elaboración de aguardiente se desarrollaron en Moçâmedes, sobre todo con los colonos provenientes de Pernambuco. ${ }^{38}$ El proceso de destilación de la caña permitió que el aguardiente estuviese presente en la agenda de exportación de ese distrito desde la década de 1860. Disponemos de una referencia de Bernadino Freire en el año de 1855, que indica su producción junto con otros productos, sin medir sus cantidades. ${ }^{39}$

Tenemos los datos de exportación de Moçâmedes para el año de 1865. La aduana de ese distrito en ese año registró una salida en un total de 148:831\$485 reis. ${ }^{40}$ De ese valor, el importe de 61:995\$400 proceden del algodón y 34:405\$000 del aguardiente. En el Gráfico 1 podemos ver los principales productos que fueron exportados por Moçâmedes en $1865^{41}$ :

38 DIAS, J. Angola. In: SERRÃO, J. E OLIVEIRA, A. M. O império africano, 1825-1890. Lisboa: Estampa, 1998. p.447-448.

39AHU. Pasta Angola. Lote 2, nº 285, noviembre de 1855. Correspondência com Bernardino Freire de Figueiredo de Abreu e Castro.

40 Moneda vigente en Portugal entre los siglos XV y XX. En 1837 se estableció que 1000 reis tendría la equivalencia de 1,62585 gramas de oro fino.

41 Datos colectados de ARANHA, Brito. Op. Cit. p.275. 


\section{Gráfico I \\ Productos exportados por Moçâmedes en 1865}

(Valores en mil reis)

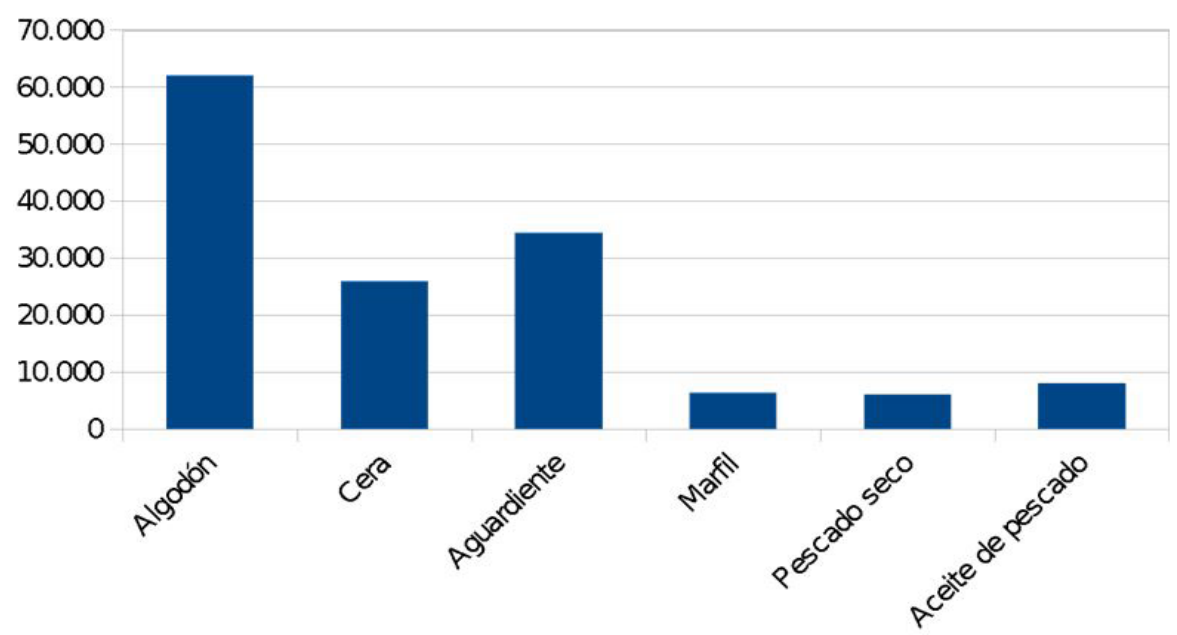

Podemos comprobar la importancia del algodón, sin duda, pero también del aguardiente que ocupaba una segunda posición en valores obtenidos y se mantuvo durante todo el siglo XIX en una posición importante en la aduana de Moçâmedes, cuando el criterio era de valores absolutos. La exportación de aguardiente aumentó a lo largo de los años hasta el inicio de la década de 1890, cuando Portugal trató de prohibir el desarrollo de cualquier actividad industrial en las colonias que pudiera competir con la industria de la metrópoli. ${ }^{42}$ Siempre hubo un desequilibrio entre la cantidad de bebida alcohólica que Angola importaba y la cantidad de aguardiente que vendía, esta siempre fue inferior a aquella. Y así, con esa normativa de 1892, se trató de disminuir sensiblemente una industria en crecimiento en Angola para asegurar un fuerte mercado de consumo a los productos portugueses.

42VALÉRIO, Nuno; FONTOURA, Maria Paula. Evolução econômica de Angola durante o segundo período colonial: uma tentativa de síntese. In: Análise Social. Vol. XXIX, 1994. p. 1197. 
A pesar de la disminución de la exportación del aguardiente de caña en Angola a partir de la última década del siglo XIX, esta fue una mercancía importante en la agenda comercial de la provincia, puesto que el destino de esa mercancía fue principalmente las otras posesiones ultramarinas en África. A finales del siglo, el aguardiente fue uno de los productos más exportados por Moçâmedes, junto con el pescado seco (siempre en primera posición), el algodón y el ganado.

\section{Tabla I}

Productos exportados por Moçâmedes en 1891, 1892, 1893

(Valores en reis)

\begin{tabular}{|c|c|c|c|}
\hline & $\mathbf{1 8 9 1}$ & $\mathbf{1 8 9 2}$ & $\mathbf{1 8 9 3}$ \\
\hline Pescado seco & $58: 957 \$ 530$ & $73: 486 \$ 359$ & $69: 431 \$ 367$ \\
\hline Ganado & I8:122\$000 & $24: 001 \$ 670$ & $29: 525 \$ 000$ \\
\hline Aguardiente & I2:606\$000 & $4: 460 \$ 270$ & I8:126\$800 \\
\hline Algodón & $20: 788 \$ 920$ & $5: 963 \$ 000$ & $10: 839 \$ 800$ \\
\hline
\end{tabular}

Estatística Geral Alfândegas de Loanda, Benguella, Mossamede e Ambriz, 1890 a 1894. Lisboa: Imprensa Nacional, 1896. p. 139-202

La Tabla I nos ofrece el valor de los productos exportados a finales del siglo XIX por la aduana de Moçâmedes, donde hay un mayor peso del pescado seco. La segunda mercancía más vendida fue el ganado, otro elemento de alimentación, seguido de un tercer producto que también se consumía, el aguardiente. Solo entonces encontramos el algodón, que sin duda fue importante en las exportaciones de Angola. El descenso lo hallamos en 1892 en las dos mercancías de origen agrícola, aunque el aguardiente sea un producto manufacturado con caña de azúcar, lo que puede explicarse justamente por los problemas con los cultivos en aquel año.

Es importante distinguir las finalidades distintas de las mercancías producidas, ya que esto puede ayudar a comprender los destinos de cada producto en la agenda de exportación. Y para eso algunas cuestiones son importantes al respecto de la producción del aguardiente, que también se aplican al pescado seco y a la exportación de 
ganado. Al analizar las exportaciones del año de 1898, notamos que salió de Angola para otras zonas en África cerca del 86,6\% del total del aguardiente; el 65,8\% del ganado; y el 99,5\% del pescado seco y sala$\mathrm{do}^{43}$. Aunque los valores cambien un poco cada año, lo más importante ahora son los valores porcentuales generales. La primera cuestión relevante es que la producción de aguardiente se dividía entre una porción que se quedaba en Angola y otra que, al ser exportada, se destinaba casi totalmente a otras zonas de África.

El aguardiente fue una mercancía que se exportaba poco para fuera del continente, teniendo como único comprador externo a Portugal, (y que figuran en las estadísticas de aduanas como posesiones portuguesas o posesiones extranjeras, Estado Independiente del Congo e islas adyacentes).

La segunda cuestión es que el aguardiente fue muy importante para el desarrollo de la dinámica económica interna de Angola y su fabricación se extendía por toda la provincia e implicaba a muchos agentes. Existían fábricas de aguardiente en la mayoría de los distritos de la provincia y en todos aquellos con presencia de una aduana, o sea, en Ambriz, Luanda, Benguela y Moçâmedes. Los únicos oficios que se encontraban también en casi todos los pueblos y distritos fueron los prestadores de servicios como alfayates, barberos, carpinteros, zapateros ${ }^{44}$. Pero ningún otro trabajo especializado, por ejemplo, las pesquerías, o las fábricas de cerámica, o gas, o tabaco existían en tantos distritos y pueblos distintos. Esto sugiere: 1) la relevancia de la actividad de producción de aguardiente y, naturalmente, indica algo sobre su consumo, cuando cruzamos esa información con el peso de la exportación de aguardiente para el comercio interno de África. 2) El impacto que esa producción podría causar en una industria portuguesa de bebida alcohólica que parecía necesitar de los merca-

\footnotetext{
43 Ver el Cuadro ${ }^{\circ} 20$ "Mappa dos valores da exportação, no anno civil de 1898, por mercadoria, destino e alfândegas". In: ANGOLA, Governo Geral da Província. Anuario Estatístico da Província de Angola 1898. Loanda: Imprensa Nacional, 1900. p.368.
}

44 Ibidem. p. 106-107. 
dos africanos para mantenerse. Esto puede explicar la directriz de la pauta de 1892, cuando fueron adoptadas medidas para transformar a Angola en un mercado cerrado a las exportaciones de Portugal, con el objetivo de desarrollar la incipiente industria portuguesa, y mientras tanto prohibir el funcionamiento de industrias en las colonias que pudiesen competir con la metrópoli ${ }^{45}$.

En el año de 1898, Moçâmedes exportó más aguardiente que Benguela (cerca de 121000 litros contra cerca de 3000 litros) ${ }^{46}$. Mientras tanto, este distrito - Benguela - tenía más fabricas que Moçâmedes, y la que más destacaba era Luanda. Como no tenemos datos de la producción total, no sabemos si Benguela producía menos que los otros lugares, a pesar del gran número de fábricas, o si la producción de este distrito estaba más destinada al consumo interno o a la exportación. Esto sugiere que Angola es el gran laboratorio para los productos alcohólicos de Portugal, tanto en las producciones como en las exportaciones.

Ese mismo año, Angola importó cerca de 205000 litros de bebida destilada (de Alemania, Francia, Holanda, Inglaterra y Portugal) y cerca de 3075000 litros de bebida fermentada, de la que se clasificaba como vino común o licoroso la increíble cantidad 2945 091,340 litros, procedentes de Portugal. ${ }^{47}$

La importancia del aguardiente para la economía angoleña se explica tanto por haber sido una de las mercancías más exportadas por Angola en el siglo XIX - aunque su valor fuera mucho más bajo que del caucho, por ejemplo - como principalmente por haber movido la economía interna, lo que deducimos de la gran cantidad de produc-

45 VALERIO, Nuno; FONTOURA, Maria Paula, Op. Cit.; CAPELA. José. O Vinho para o Preto: notas e textos sobre a exportação do vinho para a África. Porto: CEAUP. 2008.

46Ver el cuadro n. ${ }^{\circ} 20$ "Mapa dos valores da exportação, no ano civil de 1898, por mercadoria, destino e alfandêga’ In: Anuario Estatístico da Província de Angola 1898. Loanda: Imprensa Nacional, 1900. p. 368 .

47 Ver el cuadro n. ${ }^{\circ} 1$ «Mapa geral da importação pelas alfândegas do Ambriz, Benguella, Loanda e Moçâmdes, no ano civil de 1898, por mercadorias e procedências». In: AnuarioEstatístico da Província de Angola 1898. Loanda: Imprensa Nacional, 1900. p.252. 
tores. Además, fue uno de los productos más relevantes del comercio con los diversos pueblos africanos, y desde el siglo XVI. ${ }^{48}$ Así, a la vez que este producto permitió a Portugal mantener contacto con diversas poblaciones africanas mediante el comercio, el hecho de ser un producto que agradaba a los africanos permitió a Portugal imponer sus productos alcohólicos, su vino común, en sustitución al aguardiente, lo que se hizo localmente a partir de la caña de azúcar.

En cuanto al café, que también se trató de producir en Moçâmedes, fue el producto agrícola que más se destacó y el que los portugueses más probaron en Angola a lo largo del siglo XIX y principalmente del XX. No fue una mercancía importante en la agenda de exportaciones del sur de la provincia, sino del norte. O sea, casi no hubo exportaciones por el puerto de Moçâmedes en el ochocientos. Sí hubo un poco más por el de Benguela, pero muy inferiores si las comparamos con las de los puertos de Luanda y Ambriz. Al comparar algunos años de la década de 1890, por ejemplo, tenemos el siguiente cuadro de las exportaciones de café:

\section{Tabla II}

\section{Exportación de Café de la Provincia de Angola}

(valores en reis)

\begin{tabular}{|c|r|r|r|}
\hline & 1891 & 1892 & 1893 \\
\hline Luanda & I.208:229\$0I6 & I.232:502\$979 & 1.851:667\$652 \\
\hline Ambriz & $431: 595 \$ 605$ & $386: 357 \$ 921$ & $601: 116 \$ 120$ \\
\hline Benguela & $504 \$ 985$ & $144 \$ 380$ & $259 \$ 290$ \\
\hline Moçâmedes & $7 \$ 000$ & --- & $60 \$ 000$ \\
\hline
\end{tabular}

Estatística Geral das Alfândegas de Loanda, Benguella, Mossamedes e Ambriz nos annos 1890 a 1894. Lisboa: Imprensa Nacional, 1896. p. 48, 114, 177, 241.

Esa tabla muestra que la zona productora de café fue el norte de la provincia, de la cual se exportaba principalmente por los puertos

48 CURTO, José C. Álcool e escravos. Lisboa: Editora Vulgata, 2002. 
de Luanda e Ambriz. Pero también notamos que se producía café en toda la provincia, puesto que aparecía como producto exportado por las aduanas del sur, aunque con valores casi insignificantes si lo comparamos con Luanda. El café también fue un producto relevante para el proceso de ocupación territorial que Portugal trataba de desarrollar en Angola, con la imposición de esa mercancía y, en consecuencia, para el establecimiento de haciendas productoras por todo el territorio posible.

Sin embargo, en el sur se producía más algodón, el cual se convirtió en una mercancía importante de las exportaciones de toda la provincia, pero sobre todo para el distrito de Moçâmedes. Ya vimos que desde la década de 1860 hay registros de su exportación, lo que perduró durante las décadas siguientes. En 1890, se exportaron 18:243\$520 reis por la aduana de Moçâmedes; y al año siguiente, 20:788\$920.49 Aunque haya habido una disminución u oscilación en los años siguientes, pasamos a observar las exportaciones del algodón de la provincia de Angola a inicios de la década de 1890:

\section{Tabla III}

\section{Exportación de Algodón de la Provincia de Angola}

(valores en reis)

\begin{tabular}{|l|l|l|l|}
\hline & I891 & I892 & I893 \\
\hline Mossamedes & $20: 788 \$ 920$ & $5: 963 \$ \$ 20$ & $10: 839 \$ 800$ \\
\hline Luanda & $3: 836 \$ 112$ & $973 \$ 400$ & $5: 667 \$ 283$ \\
\hline Benguela & $3: 000 \$ 880$ & & $317 \$ 100$ \\
\hline Ambriz & ---- & ---- & ---- \\
\hline
\end{tabular}

Estatística Geral das Alfândegas de Loanda, Benguella, Mossamedes e Ambriz nos annos 1890 a 189. Lisboa: Imprensa Nacional, 1896. p. 48, 114, 177, 241.

49 LISBOA. EstatísticaGeral das Alfândegas de Loanda, Benguella, Mossamedes e Ambriz nos annos 1890 a 189. Lisboa: Imprensa Nacional, 1896, p.144 y 152. 
Ya es posible observar que el distrito de Moçâmedes producía más algodón que los distritos de la zona norte. Aunque esta mercancía no haya generado tantos dividendos para Portugal en el siglo XIX (lo que pasó a ocurrir en el siglo XX) como el caucho, que solo en 1893 exportó los valores de 2.116:493\$900 reis, fue también un producto importante para la implantación del sistema de ocupación de la tierra y, sobre todo, de explotación de la gente nativa y de su capacidad productiva.

Se nota en la historia de Moçâmedes ese intento de colonización mediante la imposición de un producto económico exterior revestido con una promesa de rentabilidad, pues cuando se distribuyeron las tierras a los colonos procedentes de Brasil, los primeros empezaron una producción de azúcar, aguardiente y cultivo de algodón. Bernardino Freire -el colono que intercambiaba correspondencia con el Consejo Ultramarino, por ser el jefe de la primera colonia procedente de Pernambuco- era el dueño de una granja, Los Cavalleros, una hacienda que se mostró productiva. Para empezar su producción, solicitó el envío de máquinas de deshuesar algodón, las cuales procedían de los Estados Unidos, y se destinaban a la Cordoaria Nacional en Lisboa. La compra y el envío de las máquinas se pagarían con las primeras producciones del algodón ${ }^{50}$. Lo que demuestra la importancia de dicha mercancía para el comercio internacional, puesto que valía el riesgo de una deuda del colono con el Estado portugués.

\section{El pescado seco}

Ahora bien, sin duda el producto más importante de la agenda de exportaciones de Moçâmedes durante todo el siglo XIX fue el pescado seco y salado. Además, fue una de las mercancías más exportadas de la provincia de Angola. El desarrollo de la pesca en Moçâmedes

50 AHU. Angola, Conselho Ultramarino, pasta 3, L 1, doc $n^{\circ} 260$. Correspondencia de Bernardino Freire solicitando el envío de dos máquinas de deshuesar algodón, año de 1853. 
fue de tal orden que las 22 pesquerías registradas en el año de 1859 pasaron a 84 en 1898, solo para hacerse una idea del crecimiento del sector de pesca y de la capacidad de absorber a los colonos que iban a explotar esa actividad..$^{51}$ En ese mismo año, el pescado seco ocupa la cuarta posición en valores de exportación entre las seis principales mercancías exportadas por Angola, teniendo en cuenta todos los puertos y aduanas:

51 ANGOLA. Governo Geral da Provincia. Anuário Estatístico da Província de Angola,1898. Luanda: Imprensa Nacional, 1900. p. 106-107. 


\section{Cuadro I \\ Principales mercancías exportadas por Angola en 1898}

(valores en reis)

\begin{tabular}{|l|l|l|l|}
\hline & Producto & Destino & Valor \\
\hline $\mathbf{1}$ & Caucho & Portugal & $5.603: 063 \$ 267$ \\
\hline $\mathbf{2}$ & Café & $\begin{array}{l}\text { Portugal, posesiones portuguesas e Islas adyacen- } \\
\text { tes }\end{array}$ & $758: 496 \$ 383$ \\
\hline $\mathbf{3}$ & Cera & Portugal & $304: 146 \$ 640$ \\
\hline $\mathbf{4}$ & $\begin{array}{l}\text { Pescado seco y } \\
\text { salado }\end{array}$ & Posesiones portuguesas y Portugal & $134: 735 \$ 976$ \\
\hline $\mathbf{5}$ & Cocos & Portugal & $66: 251 \$ 479$ \\
\hline $\mathbf{6}$ & Aguardiente & Posesiones Portuguesas y Portugal & $44: 852 \$ 447$ \\
\hline
\end{tabular}

Anuário Estatístico da Província de Angola 1898.

Loanda: Imprensa Nacional, 1900. p. 365

Ocupa una posición destacada el caucho, cuya explotación no duró mucho tiempo, de 1880 a 1932, y que puso a Angola en el llamado Ciclo del Caucho ${ }^{52}$. Fue la mercancía que proporcionó más renta a Portugal durante algunos de aquellos años, y entre 1887-1912 representó cerca del $64 \%$ de las exportaciones totales de la provincia de Angola ${ }^{53}$. La recolección del caucho fue movida por el proceso de industrialización de algunos países europeos y de Norteamérica y ejemplifica la participación de cada zona del mundo en ese proceso, dando cabida a países como Angola y Brasil en el suministro de materias primas. En el caso de Angola, que estuvo bajo el yugo colonial, los beneficios de este producto se destinaron a Portugal. Como sucedió con otros productos extractivos explotados en el siglo XIX, la extracción natural del caucho que se llevaba a cabo en Angola (y también en

52 SANTOS, Maciel. Borracha e tecidos de algodão en Angola, 1886-1932 - o efeito renda. In: Centro de Estudos Africanos. Porto: Universidade do Porto, 2012. Disponible en: <http://www.africanos. eu/ceaup/uploads/WP_2012_02.pdf>. Consultado el: 15 marzo 2018.

53 Ibidem. p. 5 
Brasil) no pudo competir con el caucho cultivado en Asia, por lo que dejó de ser una mercancía de exportación. ${ }^{54}$

Entre 1891 y 1903 Angola exportó una media anual superior a los 2.000:000 reis. Fue el producto que dominó la agenda de exportaciones de la provincia, como ya lo hemos dicho. Si dejamos a un lado esta mercancía y nos fijamos solo en los demás productos relevantes del comercio exterior de Angola en aquel período:

\section{Gráfico II}

Exportaciones de Angola 1891-1903

(pescado, café, algodón, aguardiente, cera y ganado)

(valores en mil reis)

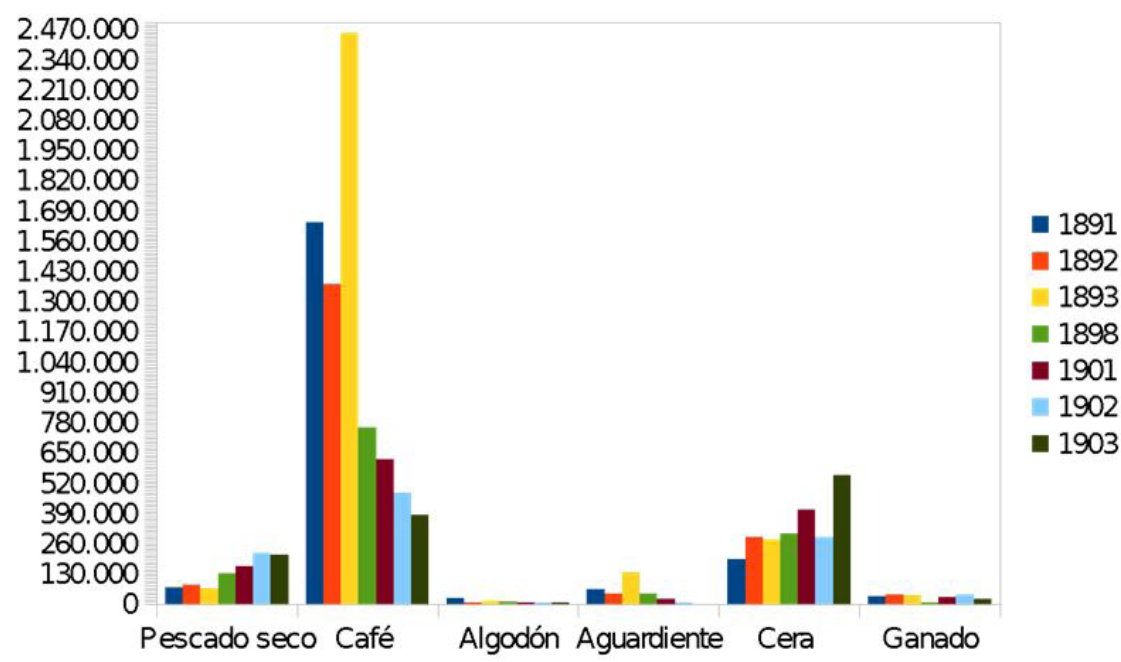

Estatística Geral Alfândegas de Loanda, Benguella, Mossamedes e Ambriz, 1890 a 1894; AnuárioEstatístico da Província de Angola 1898; Estatística do comércio e navegação de Cabo Verde, São Tomé e Príncipe e Angola, annos 1989-1905.

Después del caucho, la mercancía más exportada fue el café. A partir de 1898 se produce una reducción significativa, justamente

54 VALERIO, Nuno; FONTOURA, Maria Paula. Op. Cit. 
en el periodo en el que el caucho tiene una mayor valorización. Pero el café reanuda su producción y, a partir de 1940, se convierte en el principal producto de exportaciones de Angola, hasta 1972, cuando se inicia el ciclo del petróleo..$^{55}$ La cera se mantiene en ascensión durante ese periodo, pero así como otros productos de extracción animal, vegetal o mineral (como el marfil, la goma y los minerales) sufre grandes oscilaciones provocadas por el mercado, por la oferta repentina de nuevas zonas, y también por el agotamiento de las fuentes debido a los excesos de explotación.

En el Gráfico III, llama la atención el pescado seco. Aunque no se exportase tanto como el café, fue un producto que mantuvo una línea ascendente, revelando un crecimiento del sector de la pesca, así como cierta estabilidad. Si la exportación de ganado oscila un poco, con un descenso en el año 1898, también muestra cierta estabilidad durante el intervalo de diez años. Incluso más que el aguardiente, que era objeto de mayor interferencia e intención de control por parte del estado colonial, como ya lo hemos visto.

Podemos observar, por último, que el pescado seco tiene una participación muy significativa en la agenda de exportaciones de Angola, teniendo en cuenta que no se trataba ni de un producto de extracción, ni de un producto agrícola de interés comercial internacional, ni tampoco de una mercancía de larga tradición de comercio africano, como el aguardiente. Sin embargo, fue el que permitió el desarrollo de Moçâmedes y su inclusión definitiva en el sistema-mundo capitalista en el siglo XIX, después del fin del comercio de esclavos. La industria del pescado se constituyó en un comercio de alimento

55 SANTOS, Maciel. Op. Cit. 
con otras provincias africanas, que, a su vez, producían diversos géneros comerciales importantes para la agenda internacional.

\section{Historia de las pesquerías y de la exportación de pescado}

Hasta aquí hemos visto que el pescado se había constituido en un importante punto de la agenda de exportaciones de Angola y lo hemos comparado con otros productos exportados, para analizar los valores que dicha mercancía producía. Debemos preguntarnos entonces por qué la industria pesquera se instauró en Moçâmedes, un sitio elegido por los portugueses para la implantación de una colonia agrícola. También por qué se desarrolló una industria pesquera en un sitio donde no había tradición de pesca, sino de cría de ganado por los pueblos locales.

El primero que fundó una instalación pesquera en Moçâmedes lo hizo en 1843: se llamaba Fernando José Cardoso Guimarães, un algarvio que se trasladó a Moçâmedes para montar una factoría en sociedad con la famosa negociante de Luanda, Anna Joaquina dos Santos e Silva. Era natural de Quelfes, un distrito de Olhão en Portugal, de la zona conocida como Algarve. Un año más tarde, con el origen de esta iniciativa y para estimular la colonización, la reina de Portugal, D. Maria II, envió a Moçâmedes anzuelos para los pescadores $^{56}$. La posibilidad de capturar pescado y, además, de exportarlo a otros distritos y a otras provincias, la hemos podido demostrar con el envío a Luanda de dos remesas de pescado seco en 1846: en enero fueron 80 motetes; y en agosto, más de 70. Algunos años después, en 1848, Moçâmedes envió a Luanda 481 motetes de pescado seco y salado, cifra que fue aumentando y que posiblemente estimuló la llegada de más pescadores algarvios al sur de Angola ${ }^{57}$.

56 MENDES, António. Pesca em Portugal: Ultramar - umapontamento histórico. In: Revista Portuguesa de CiênciasVeterinárias. n 100, 2005. p. 20.

57 FELNER, Alfredo. A indústria da pesca na costa de Mossamedes. In: Gazeta das Colônia. Ano II, $n^{\circ} 27$ e 28,1925 . «Motete» era el nombre para un conjunto amarrado de diez pescados. 
Los primeros intentos de pesca y salazón de pescado en Moçầmedes permitieron que, antes del mayor flujo migratorio de los años 1860, ya en 1859, la región contara ya con 22 instalaciones pesqueras. Cerca de la mitad de la población era de pescadores que explotaban el sur de Angola y que habían llegado desde su tierra de origen, las ciudades y pueblos pesqueros del sur de Portugal, pero también de las llamadas islas adyacentes de Azores y de Madeira ${ }^{58}$. Cuando los pescadores algarvios empezaron a llegar en gran cantidad a Moçâmedes, también se instalaron factorías en Porto Pinda y Bahia dos Tigres. A ellos se juntaron algunos inmigrantes pescadores de la isla de Madeira, que prefirieron montar instalaciones en el litoral a quedarse en el altiplano de Huilla, adonde habían sido enviados para trabajar en la tierra ${ }^{59}$.

Los datos de las estadísticas de aduanas muestran la importancia de la exportación por el puerto de Moçâmedes de pescado seco desde los principios de su creación. Con el tiempo, otros productos derivados, como el aceite de pescado, también fueron exportados. La mayoría de los colonos y administradores aún parecían interesarse por la producción agrícola, como se puede notar por el informe del Visconde de Sá da Bandeira, en 1859, que resaltaba los diminutos progresos de la agricultura en la región y la presencia de solo tres ingenios de azúcar ${ }^{60}$. Algunos años más tarde, en 1867, el gobernador del distrito Joaquim José da Graça escribía:

58 MEDEIROS, Isabel. op. cit.

59 MENDES, Antonio. op. cit. p.20.

60 SÁ DA BANDEIRA, Visconde de. Relatório de 1859. apud ARANHA. Brito. Op. Cit. p.243. 
A agricultura d'este districto é quasi exclusivamente de algodão. A cannasacharina cultiva-se em pequeña escala; o café só em uma fazenda de Capangombe-Maconjo pertencente à casa da firma comercial Nogueira, Brochado \& Comp ${ }^{a}$, se cultiva mais culdadosamente, mas os seus productos só tem aparecido como amostras, sendo esta de boa qualidade ${ }^{61}$.

Se conoce la importancia de los productos de la agricultura y de la extracción vegetal, animal y mineral para la sociedad angoleña. Además, fueron importantes productos exportados por todos los puertos de la provincia. Cuando hablamos del puerto aduanero de Moçâmedes, nada se compara, en el siglo XIX, a los valores derivados de los pescados, que, además tuvieron una producción ascendente, como podemos mirar en los datos siguientes:

Tabla IV

Exportaciones de Pescado Seco de Moçâmedes

(valores en escudos)

\begin{tabular}{|c|c|c|}
\hline Años & Cantidad en tonelada & Valores \\
\hline $1861-65$ & 1.155 & 30.439 \\
\hline $1866-70$ & 915 & 33.745 \\
\hline $1871-75$ & 2.135 & 82.951 \\
\hline $1876-80$ & 1.907 & 78.921 \\
\hline $1881-85$ & 3.425 & 126.513 \\
\hline $1888-90$ & 4.723 & 189.092 \\
\hline $1891-95$ & 5.755 & 327.720 \\
\hline $1896-1900$ & 14.175 & 617.332 \\
\hline
\end{tabular}

FELNER, Alfredo. A indústria da pesca na costa de Mossamedes. In: Gazeta das Colônia. Ano II, nº 27 e 28, 1925.

61 GRAÇA, Joaquim José da., Relatório de 1867 referente ao primeiro ano de seu governo, transcrito por ARANHA, Brito. Op. Cit. p.250. 


\begin{tabular}{|c|c|c|}
\hline $1901-05$ & 23.789 & 856.000 \\
\hline $1906-10$ & 23.780 & 935.000 \\
\hline $1911-15$ & 28.671 & 1.107 .000 \\
\hline $1916-20$ & 38.736 & 2.754 .000 \\
\hline
\end{tabular}

Estos son datos divulgados por Alfredo Felner, que presenta los valores en la moneda portuguesa escudo, adoptada por Portugal a partir de 1911. Notamos por estos datos que hay solo dos pequeñas reducciones en la producción de pescado seco; la primera en el segundo quinquenio cuando la producción disminuyó 239 toneladas, sin reflejarse en los valores recaudados; más tarde, entre el tercero y el cuarto quinquenio, la producción disminuyó 228 toneladas, con un pequeño impacto en los valores recaudados. No obstante, en el cuadro global, observamos un crecimiento de esta mercancía.

Para entender esa estabilidad, o sea, el continuo crecimiento del sector en ese periodo, volvemos al Cuadro I para observar el destino de las principales mercancías exportadas por la provincia de Angola. Mientras el caucho, la cera y los cocos se dirigían exclusivamente al mercado extranjero, y Portugal era su comprador, el pescado seco y el aguardiente tenían a las propias posesiones africanas como principal destino. A tales productos debemos añadir el ganado, que tuvo otros puertos de África como principal destino.

El pescado seco y salado fue una mercancía realmente importante para el comercio con las poblaciones nativas africanas, y se convirtió en un producto esencial de su alimentación, por supuesto junto con la carne de ganado. Aquí volvemos a hablar de la necesidad del suministro de proteína animal para la dieta humana y de las alternativas que se desarrollan para la tarea de producirla.

Cuando los españoles desarrollaron la industria pesquera en $\mathrm{Ca}$ narias, durante los siglos XVII y XVIII, una de las motivaciones fue la necesidad de alimentar con proteína animal a una población ibérica que encontró, en cierto momento, dificultades para el abastecimiento de carne. Esta pudo haber sido una de las razones por las que el Atlántico hubiera sido explotado en su potencialidad de suministro 
de alimento, lo que resultó además en una expansión, una cierta diáspora, de pueblos europeos. La historia de la pesca de esta zona - el Atlántico centro-oriental ${ }^{62}$ - provocó cierto impacto en el archipiélago y contribuyó a su desarrollo. En consecuencia, el progreso de las actividades pesqueras y otras actividades derivadas de ella, como la industria naval, permitieron la oferta de alimentos a una sociedad en crecimiento, estimulando además, el comercio ${ }^{63}$.

En lo que respecta a Angola y Portugal, cabe resaltar que el comercio de alimentos fue fundamental para el desarrollo tanto de una población como el de una región y nación. Pero tal comercio también fue utilizado como una base para la expansión portuguesa y para el proyecto de colonización promovido en África. Por esta razón, la producción de pescado, ganado y aguardiente fue tan importante en la historia de Angola: se trataba de productos de consumo interno en África que siempre estuvieron en las exportaciones de la provincia, durante el siglo XIX y parte del XX, y que estimularon una circulación comercial dentro del continente africano entre pueblos distintos.

Por último, junto con estos productos de consumo que también se exportaban, habían otros productos de primera necesidad para la alimentación que se cultivaban en el campo, como patata, cebolla, mandioca, hortalizas y diversos otros géneros. Estos también fueron producidos en Moçâmedes para el consumo local y se comercializaron internamente y también con el extranjero. Los alimentos fueron importantes para el comercio en Angola, sobre todo cuando producían pequeñas cantidades de valores. Podemos mencionar, por ejemplo, que a finales de 1854 Moçâmedes empezó a ser visitada por embarcaciones balleneras que faenaban cerca de la isla Santa Helena y que iban al nuevo puerto en el sur de Angola para abastecerse con alimentos de las huertas locales, lo que movía la agricultura, el comercio y la industria pesquera ${ }^{64}$. Por lo que el comercio de mercancías en

62 ONU, Op. Cit. p.15.

63 SANTANA Juan Manuel; SANTANA. Germán. Op. Cit.

64 FELNER, Alfredo. Op. Cit. p.24 
pequeña cantidad, como de alimentos para la supervivencia, puede haber sido uno de los motores propulsores para el establecimiento y el desarrollo de Moçâmedes como una ciudad en el sur de Angola.

\section{Conclusión}

La importancia de la producción de pescados seco en Moçâmedes no se encuentra solo en el movimiento financiero que promovió, sino también en otros significados y consecuencias que las relaciones comerciales permitieron, como, por ejemplo, la presencia de productos de Angola en diversos lugares africanos. Además, el suministro de alimentos, como el pescado seco, posibilitó la permanencia de un proyecto europeo en tierras africanas que se asentaba en un comercio local.

De hecho, el comercio de géneros alimenticios, que incluye a los pescados, no ha sido algo banal. En la década de 1960, por ejemplo, el pescado seco llegó a representar el 6\% de las exportaciones de Ango$\mathrm{l}^{65}$. Con la actual dependencia económica del país de las exportaciones del petróleo, el sector de pesca vuelve a ganar importancia, por lo que, en el año de 2017, se inauguró la Academia de Pesca e Ciências do Mar, justamente en Moçâmedes.

La potencialidad para una industria pesquera a gran escala, junto con la necesidad creciente de alimentación para una población mundial en desarrollo y una historia de la pesca en África constituyen la coyuntura en que se creó dicha Academia en el sur de Angola. Se trata de un instituto de enseñanza superior, cuyo objetivo declarado es la formación de especialistas en pesca, procesamiento de pescado y explotación de recursos acuáticos. Esta acción resultó de una alianza entre el gobierno angoleño y el de Polonia, y contó aun con recursos

65 MEDEIROS, Isabel. op. cit. p.35. 
de capital y recursos humanos extranjeros de países como China y Portugal. ${ }^{66}$

Esta Academia de Pesca es una nueva institución que se funda en la ciudad que abrigó, entre los años 1937 y 1952, la Escola Prática de Pesca e Comércio de Moçâmedes, una iniciativa de menor dimensión, sin duda, una vez que se trataba de un curso de nivel básico con una duración de cinco años y que se realizaba al concluir el nivel primario de cuatro años. Sin embargo, aquella iniciativa también se desarrolló con la presencia de capital extranjero, una vez que se vivía en el contexto del colonialismo, o sea, en un momento en que Angola se encontraba bajo el yugo de Portugal.

El contexto político angoleño cambió mucho en estos 80 años, pero la creación de la Academia de Pesca, que se afirmó como un sistema de enseñanza e investigación, nos indica la permanencia de capital de países europeos en el continente africano, ahora también relacionados con las actividades de pesca. De la misma manera, también nos indica la importancia de este sector para la economía angoleña y mundial.

\section{Bibliografia}

AHU. Angola. Conselho Ultramarino, 1. 15, n ${ }^{\circ} 35$

AHU. Pasta Angola. Correspondênciacom Bernardino Freire de Figueiredo de Abreu e Castro. Lote 2, $\mathrm{n}^{\circ}$ 285, doc. denovembro de 1855.

AHU. Pasta Angola. Lote 2, $n^{\circ}$ 285, novembro de 1855. Correspondênciacom Bernardino Freire de Figueiredo de Abreu e Castro.

AHU. Angola, Conselho Ultramarino, pasta 3, L 1, doc $\mathrm{n}^{\circ} 260$. Correspondencia de Bernardino Freire solicitando el envío de dos máquinas de deshuesar algodón, año de 1853.

ANGOLA, Governo Geral da Província. Anuario Estatístico da Província de An-

66Véase<http://pt.rfi.fr/angola/20170717-angola-inaugura-academia-de-pescas-e-ciencias-do-mar>. Consultado el 15 marzo 2018. 
gola 1898. Loanda: Imprensa Nacional, 1900.

LISBOA. EstatísticaGeral das Alfândegas de Loanda, Benguella, Mossamedes e Ambriz nos annos 1890 a 189. Lisboa: Imprensa Nacional, 1896

ONU. El estado mundial de la pesca y la acuicultura 2016. Contribución a la seguridad alimentaria y la nutrición para todos. Roma: 2016. Disponible en: <http://www.fao.org/publications/sofia/sofia/es/>. Consultado el: 30 enero. 2018.

ALEXANDRE, Valentin. A desagregação do Império Luso-Brasileiro. In: SERRÃO, J. E OLIVEIRA, A. M. Nova História da Expansão Portuguesa: 0 Império Africano, 1825-1890. Lisboa: Editorial Estampa, 1998.

ARANHA, Brito. Memórias histórico-estatísticas de algunas villas e povoações de Portugal. Lisboa: Livraria de A. M. Pereira, 1871.

AZEVEDO, José Manuel de. Colonização do sudoeste angolano: do deserto no Namibeaoplanalto da Huíla, 1849-1900. Tesis Doctoral. Salamanca: Universidad de Salamanca, 2014.

BRICHTA, Laila. Una travesía hasta Moçâmedes: migraciones atlánticas y la creación de una ciudad en el sur de Angola en el siglo XIX. In: Batey: Revista Cubana de Antropología Sociocultural. Vol. 11, año 2018.

CAPELA. José. O Vinho para o Preto: notas e textos sobre a exportação do vinho para a África. Porto: CEAUP. 2008.

CUNHA, Pedro Alexandrino. Exploração dos portugueses na costa occidental D'Áfricaem 1839. In: Annaes Marítimos e Coloniais. Lisboa: Imprensa Nacional, $\mathrm{n}^{\circ} 12$, $5^{\text {a }}$ série, 1845.

CURTO, José C. Álcool e escravos. Lisboa: Editora Vulgata, 2002.

DELGADO, Ralph. História de Angola. Banco de Angola. Lisboa, 1978.

DIAS, J. Angola. In: SERRÃO, J. E OLIVEIRA, A. M. O império africano, 18251890. Lisboa: Estampa, 1998.

ESTERMANN, C. Etnografia do Sudoeste Africano. Lisboa: Junta de Investigação do Ultramar, vol. III, 1961.

FELNER, Alfredo. Apontamentos sobre a colonização dos planaltos e litoral do Sul de Angola. Lisboa: AgênciaGeral do Ultramar, 1940.

FELNER, Alfredo. A indústria da pesca na costa de Mossamedes. In: Gazeta das Colônia. Ano II, nº 27 e 28, 1925.

FERREIRA, Roquinaldo. Abolicionismo versus colonialismo: rupturas e continuidades em Angola (século XIX). In: GUEDES, Roberto(org.) 
África: brasileira e portuguesa - séculos XVI -XIX. Rio de Janeiro: Mauad X. 2013.

GRAÇA, Joaquim José da. Relatórios de seugoverno. apud ARANHA, Brito. Memórias histórico-estatísticas de algunas villas e povoações de Portugal. Lisboa: Livraria de A. M. Pereira, 1871.

GUIMARÃES JUNIOR, Antonio Joaquim. Memorias sobre a exploração aosul da costa de Benguela na África Occidental e fundação do primeiro estabelecimento comercial na Bahia de Mossamedes. Lisboa: Tipografia de F. C. A, 1842.

LUZ SORIANO, Simão José da. Memória sobre os sertões e a costa sul de BenguellanaProvíncia de Angola”. In: Annaes Marítimos e Colonias. Lisboa: Imprensa Nacional, $n^{\circ} 3,6^{a}$ série, 1846.

MARQUES, João Pedro. Uma Fazenda em África. Lisboa: Editora Porto, 2012.

MEDEIROS, Isabel. Contribuição para o estudo da colonização e pesca no litoral de Angola aosul de Benguela. In: Col. Estudos Ensaios e Documentos. IICT, Lisboa, n. 140, 1986.

MENDES, António. Pesca em Portugal: Ultramar - umapontamento histórico. In: Revista Portuguesa de CiênciasVeterinárias. $\mathrm{N}^{\circ}$ 100, 2005.

MILLER, Joseph. Way of Death: merchant capitalism and the Angola slavry trade, 1730-1830. Wisconsin: University of Wisconsin Press, 1988.

PACHECO, Duarte.Esmeraldo de Situ Orbis. Lisboa, Imprensa Nacional, 1892.

SANTANA Juan Manuel e SANTANA. Germán. La pesca en el banco sahariano, siglos XVII y XVIII. Madrid: Catarata, 2014.

SANTOS, Maciel. Borracha e tecidos de algodãoem Angola, 1886-1932 - o efeito renda. Centro de Estudos Africanos. Porto: Universidade do Porto, 2012.

TORRES, Manuel Júlio. O Distrito de Moçâmedes: nas fases da origem a da primeira organização (1485-1859). Lisboa: AgênciaGeral do Ultramar, 1950.

VALÉRIO, Nuno; FONTOURA, Maria Paula. Evolução econômica de Angola durante o segundo período colonial: uma tentativa de síntese. In: Análise Social. Vol. XXIX, 1994.

VILELA, José (1923) apud MENDES, António. Pesca em Portugal: Ultramar: umapontamento histórico. In: Revista Portuguesa de CiênciasVeterinárias. $\mathrm{N}^{\mathrm{o}} 100,2005$.

VISCONDE DE GIRAÚL. Colonização europeia da província de Angola. Lisboa: Imprensa Nacional, 1901.

WALLERSTEIN, Immanuel. Capitalismo histórico e civilização capitalista. Rio 


\section{de Janeiro: Contraponto, 2001.}

Recibido en: 31/03/2018 - Aprobado en: 08/10/2018 